\title{
x Sustainability and cultural heritage buildings
}

\author{
Paulo B. LOURENÇO, Jorge M. BRANCO, Ana COELHO \\ ISISE, Department of Civil Engineering, University of Minho, Guimarães, Portugal
}

\section{$\mathrm{x.1}$ Introduction}

Conservation of cultural heritage buildings is a demand from society, which recognizes this heritage as a part of their identity, but it is also an economical issue. In Europe, tourism accounts for $10 \%$ of the GDP and 12\% of the employment, if linked sectors are considered [x.1]. The EU is the world's number one tourist destination, with $40 \%$ of arrivals in the world and with 7 European countries among the top ten [x.2]. According to the WTO estimates, international tourist arrivals in Europe will increase significantly. The built European heritage, namely monuments or historical centres, is a main attractor for tourism, with $45 \%$ of the UNESCO World Heritage sites within the EU. Therefore, the need for their conservation is unquestionable.

Cultural heritage buildings are particularly vulnerable to disasters because they are deteriorated and damaged, they were built with materials with low resistance, they are heavy and the connections between the various structural components are often insufficient. The main causes for damage are the lack of maintenance and water-induced deterioration (from rain or rising damp), soil settlements and extreme events such as earthquakes, but there are many other causes of damage, namely: high stresses due to gravity loading, alterations in lay-out or construction, cyclic environmental actions, climate change, physical attack from wind and water, chemical and biological attack, vegetation growth, fire, floods, vibration and micro-tremors, and anthropogenic actions. Still, extreme events often lead to disasters, in light of the high vulnerability.

A disaster is an event caused by nature or man that causes great physical damage, destruction or loss of life, or a drastic change in the natural environment. Danger is the level of threat to life, property or environment, but it is important to understand that danger is not correlated to damage, and that disasters are the result of poor risk management. Risk management involves, first, the perception and communication of risk to society. It is then essential to have proper tools for assessment and diagnosis, but also to define a set of possible solutions, and their costs, to implement a risk mitigation strategy. Over the past 30 years, economic losses due to disasters have increased tenfold, while earthquakes caused 80,000 deaths / year in the last decade (Figure 1). Studies indicate that investment in mitigation provides society an average of four times the amount invested [x.3]. In addition to savings to society, the US Federal Treasury can redirect an average of 3.65 times the money spent on mitigation resulting from disaster relief costs and tax losses avoided. This result was published in December 2005 in a report prepared by the Multi-hazard Mitigation Council of the National Institute of Building Sciences, called "Natural Hazard Mitigation Saves" [x.4]. The report was the culmination of a 3-year, Congressionally-mandated independent study. Another interesting example is given by the World Bank [x.5] and United Nations where a study about retrofitting of buildings to increase earthquake resiliency provides a cost-benefit ratio of up to eight, for a discount rate of 5\%. [x.6] on the presentation of the same study, provides a benefit-cost ratio of 4.6 for earthquakes, based in Istanbul, and stressed the obvious fact that the world population exposed to earthquakes will rise dramatically from 2000 to 2050. As risk mitigation of the existing built heritage implies a large investment, it is necessary to set priorities and consider an extended period of time to get communities physically, socially and economically resilient. 

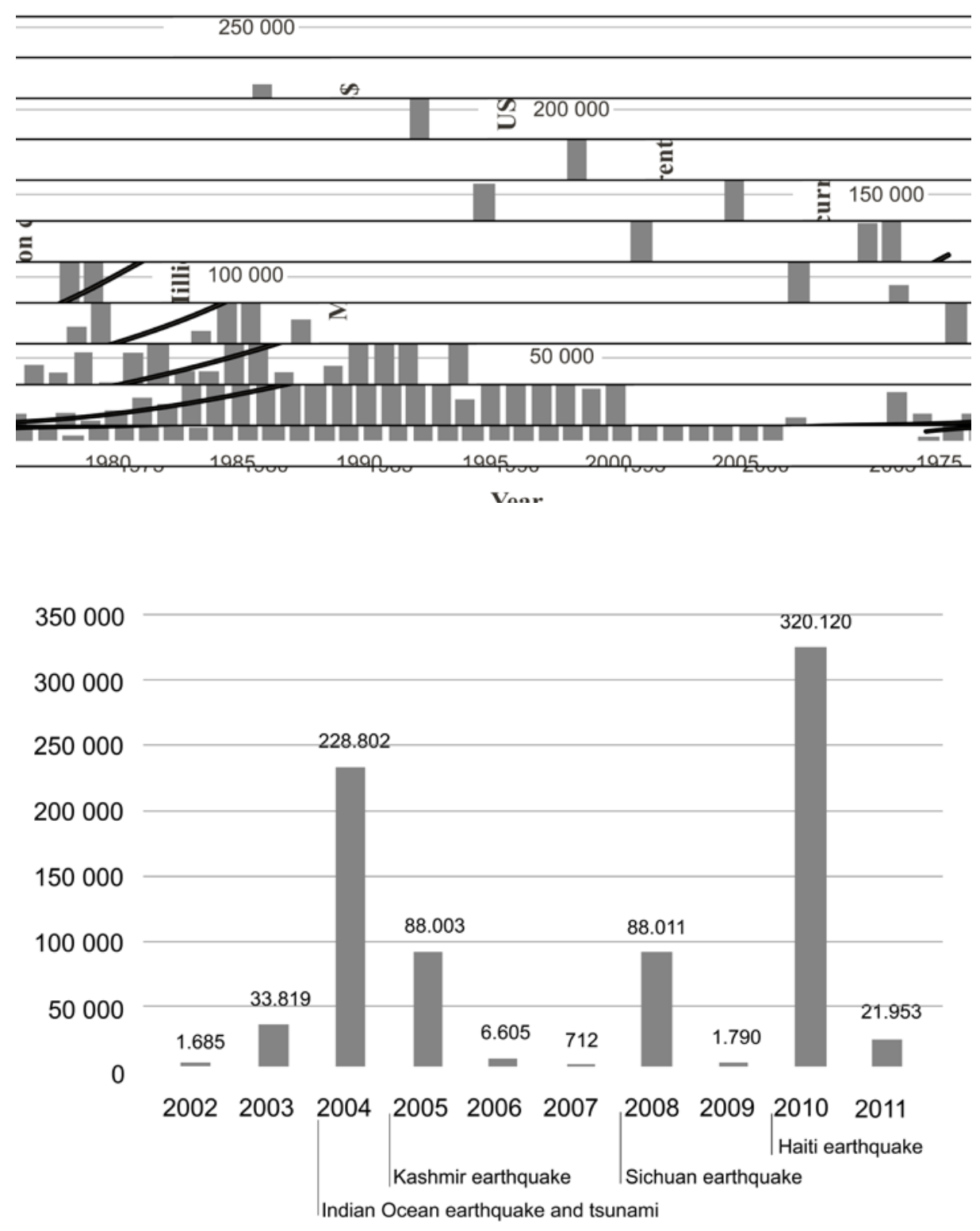

Figure $x-1$

Effects of disasters
Economic losses
associated with
natural disasters

(Image: [x.7])

Figure $x$-2

Effects of disasters Number of deaths in the last ten years

(Image: [x.8])

The approach for risk reduction is known, being necessary to: (i) characterize the existing built heritage; (ii) perform simplified analysis at the territorial level to estimate the vulnerability and risk of this heritage; (iii) in cases identified with higher risk in the previous step, perform detailed analyses to confirm the vulnerability and risk, (iv) define a plan with long-term intervention measures and their costs, taking into account the observed risk, (v) implement the plan, with periodic reviews of time and costs, considering the economic constraints and the costs incurred in actual interventions. It is also true that a strategy like this requires political and societal commitment to become reality.

Another important question is if heritage buildings can be somehow related to the sustainability agenda. It is currently accepted that the improvement of the energetic performance of existing building plays an important role in the decrease of the overall energy consumption, which is a key feature of the sustainability profile of buildings. Nevertheless, heritage buildings have a cultural and symbolic function that might limit its comfort requirements, being often energetic performance a minor concern in the conservation and rehabilitation of monuments and other protected buildings. On the contrary, the safety of cultural heritage assets cannot be negotiated and several interventions 
are made for this purpose. The same does not hold for minor assets and historic city centres, where comfort, re-use and rehabilitation should address energetic performance.

Despite the minor importance on energetic issues for monuments and major cultural heritage assets, intervention on heritage buildings may be an important part of sustainability policies, as far as it produces impacts on the different sustainability dimensions: economy, environment and society.

This chapter presents an overview of the role of cultural heritage buildings in the sustainability goals, focusing on the construction materials, on the methodology of interventions, on the application of life-cycle assessment tools to existing buildings and, finally, on a summary of the impacts produced on the sustainability dimensions. Because it can be an unusual topic for some engineers, it also intends to provide a background on cultural heritage and historic preservation engineering. Only with a correct understanding of the global methodology for the preservation of cultural heritage buildings someone can seek for sustainability in this specific are of engineering.

\section{x.2 Definitions}

\section{x.2.1 Cultural heritage conservation specificities}

A first relevant question is what is "cultural heritage”? The concept is reviewed by [x.9], meaning a cultural resource involving technical, artistic and spiritual merits and a landmark providing identity to cultures, world regions and towns. Cultural heritage provides also a document on ancient knowledge, practices, culture, technology and history and a live document of outstanding cultural and technical achievements, from which we can still learn and improve. Finally, cultural heritage is an economic resource with extremely large capacity to generate secondary economy, while contributing to cultural diversity, global cultural wealth and human development.

Cultural heritage can be distinguished in the Built Environment (such as buildings, townscapes and archaeological remains), the Natural Environment (such as rural landscapes, coasts and shorelines, and agricultural heritage) and Artefacts (such as books and documents, objects and pictures). The first type is referred to next as the built cultural heritage and in order to people understand, value, want to care for and enjoy, the idea of authenticity, i.e. truth free of deviation, as well as novelty and creativity arises. Depending on the nature of the cultural heritage, its cultural context, and its evolution through time, authenticity judgments may be linked to the values of a great variety of sources of information, such as form and design, materials and substance, use and function, traditions and techniques, location and setting, spirit and feeling, or other internal and external factors.

The built cultural heritage thus includes archaeological remains, monuments, dwellings and vernacular buildings, groups of buildings, ancient city centres, and historical urban texture but also outstanding engineering works from antiquity to present, industrial heritage from 19th and 20th centuries, 20th century heritage in steel or reinforced concrete and even modern heritage. Value is not related with age or with the fact of an asset being or not listed. Still, it is obvious that most of the existing built heritage is made with the so-called traditional materials (masonry and timber) and special attention is devoted here to these materials.

The concept of a "historic monument" embraces not only the single asset but also urban or rural setting in which is found the evidence of a particular civilization, a significant development or a historic event. The criterion of "historic significance" is often used to justify the need to protect individual objects or groups of buildings. Despite the extension of cultural heritage legislation and protection to groups of buildings and urban spaces, despite the listing (inventory) of complete town 
centres, the instruments and the application of monument protection is still fundamentally 'object' centred. A significant risk and threat for groups of buildings, urban spaces and isolated buildings tends to affect less outstanding objects and more the loss of density, historic nature, complexity and quality of urban fragments [x.10]. The importance of the building stock as cultural heritage and the consideration of the building stock as 'resource' are discussed in detail in [x.11].

Conservation is defined in the Nara Charter [x.12] as "all efforts designed to understand cultural heritage, know its history and meaning, ensure its material safeguard and, as required, its presentation, restoration and enhancement”. A more technical oriented definition can be: all actions or processes that are aimed at safeguarding the character-defining elements of a cultural resource so as to retain its heritage value and extend its physical life. A different concept is restoration, an action or process of accurately revealing, recovering, or representing the state of a cultural resource or of an individual component, as it appeared at a particular period in its history, while protecting its heritage value. Restoration is a complex concept for the built heritage as this heritage was hardly produced in any given period of time. On the contrary, the built heritage evolved together with the society, the needs, and the building styles and techniques. The concept of restoration is in fact very controversial and encompasses many different interpretations, ranging between reconstruction / full "repristination", even involving the reconstruction of parts historically collapsed or which may have never been actually built, to that of minimal intervention oriented to strict preservation / conservation. The understanding of restoration connected to reconstruction / repristination is clearly out-of-fashion and in contradiction with modern conservation principles.

Other technical concepts are stabilization, an action aimed at stopping a deteriorating process involving structural damage or material decay (also applied to actions meant to prevent the partial or total collapse of a deteriorated structure), repair, an action to recover the initial mechanical or strength properties of a material, structural component or structural system (also applied to cases where a structure has experienced a deterioration process having produced a partial loss of its initial performance level), and strengthening, an action providing additional strength to the structure (needed to resist new loading conditions and uses, to comply with a more demanding level of structural safety, or to respond to increasing damage associated with continuous or long term processes). In the context of conservation of historical structures, repair is not meant to correct any historical deterioration or transformation (including those manmade) which only affects the appearance or formal integrity of the building and does not compromise its stability. Repair should be only used to improve structures having experienced severe damage actually conveying a loss of structural performance and thus causing a structural insufficiency with respect to either frequent or exceptional actions. Strict conservation will normally require stabilization or repair operations. Conversely, rehabilitation will frequently lead to strengthening operations. Rehabilitation is defined as the upgrading of a building to comply with modern uses and standards. Rehabilitation constitutes in fact an activity substantially different to conservation and frequently leads to alter the structure to an extent incompatible with the strict conservation principles.

Rehabilitation is also often defined as an action or process of making possible a continuing or compatible contemporary use of a cultural resource or an individual component, through repair, alterations, and/or additions, while protecting its heritage value. The problem with this definition is that making possible a modern use according to modern standards and codes may be incompatible with sound protection of heritage value. Rehabilitation will often require significant transformation with loss of authenticity and cultural value. Still, a cost-benefit analysis must be made in all cases, as the modern requirement of a living cultural heritage allows a change of use and it is, economically, impossible to maintain the built heritage only for touristic and "monumental" use. The built cultural heritage includes residential and commercial buildings, meaning that, even if the regulations for new buildings cannot be blindly adopted, adequate performance is required in terms of comfort, accessibility and thermal efficiency, among others, and adequate performance must be 
demonstrated in terms of structural safety, fire protection, and other non-negotiable requirements. Nevertheless, the intervention on cultural heritage buildings may be regulated by specific policies and rules, which tend to vary according to the classification and the location of the building.

\section{x.2.2 Rehabilitation and sustainability}

Sustainability may be assessed throughout three different perspectives, which should work in combination: economical, environmental and social impacts. Rehabilitation of cultural heritage buildings certainly produces impacts in the three categories, being some of them more remarkable than the others.

On the economical point of view, rehabilitation certainly represents a significant initial investment, due to the specifics imposed by heritage buildings, including keeping their original features, using traditional techniques and materials, difficult accessibilities and unexpected findings during the works, among others. Rehabilitation is often more expensive than new construction, partly because many interventions are too extensive and fail to reuse the original fabric. The investment in the rehabilitation of ancient buildings has important economical outcomes, such as the creation of jobs (considering that the use of traditional techniques demands more manpower than modern techniques), local employment (small and medium enterprises are mode competitive to these works than major contractors) and the value added to a certain region (due to the increase of its touristic potential and/or the improvement of the region self-esteem), see also [x.13]. It is also noted that, according to the Whitestone's Facility Cost Forecast System originally developed for the US Army, the cost of a building per year is $6 \%$ of the initial cost, including $35 \%$ for operation, $46 \%$ for preventive maintenance, repair and part replacement, and 19\% for recapitalization. Even if the cost of maintenance is lowered from about 3\% per year to a value of only $1-2 \%$ per year, by the fact the building heritage is there (and has no operation costs), significant costs apply. Therefore, the sensible option is to rehabilitate and reuse, with a positive economic impact.

Concerning the environmental issues, the rehabilitation of ancient buildings produces usually lower impact than making a new building. In fact, rehabilitation is a form of reuse of an existing fabric, thus extending its life span. Conservation works are frequently limited to surgical interventions, demanding few material quantities and low amounts of energy, which cause very low environmental impacts. Also, efficient rehabilitation can provide a similar result. It is noted that the use of traditional materials and techniques, when applicable, is characterized by a very low environmental impact, due to the low amounts of energy required to its manufacture and processing.

On the social perspective, rehabilitation of cultural heritage buildings may be analysed under two major aspects: the valorisation of a region and the creation of jobs. On the local valorisation issue, it is supported by the fact that people are likely to feel a higher connection to a place and its history, throughout the rehabilitation of historical buildings or urban texture. The increase in awareness for history and traditions may have remarkable positive impacts in a society as well. The creation of jobs, in addition to the economical benefits, also helps in people fixation to a certain region, which may help to boost the region social performance. Thus, it is possible to provide better quality of life to the users of a building or at urban scale, by revitalization of economic activities, by attracting new users or by providing new urban equipment.

\section{x.3 Traditional materials and sustainability}

Masonry and timber are the oldest building materials that still find wide use in today's building industries. Important new developments in materials and applications occurred in the last decades but the techniques are essentially the same as the ones developed some thousand years ago. Ancient buildings are frequently characterized by a remarkable durability, which enabled them to remain in 
a good condition throughout long time periods. The role of masonry and wood in sustainability issues is described in this section.

\section{x.3.1 Masonry}

Innumerable variations of masonry materials, techniques and applications occurred during the course of time. The influence factors were mainly the local culture and wealth, the knowledge of materials and tools, the availability of material and aesthetic reasons. The most important characteristic of masonry construction is its simplicity. Laying pieces of stone or bricks on top of each other, either with or without cohesion via mortar, is a simple, though adequate technique that has been successful ever since remote ages. Other important characteristics are the aesthetics, solidity, durability and low maintenance, versatility, sound absorption and fire protection.

The first masonry material to be used was probably stone. Evolution of housing was from huts, to apsidal houses and, finally, to rectangular. Several legacies of stone masonry survived until present as testimonies of ancient and medieval cultures. In addition to the use of stone also mud brick started to be used as a masonry material. It was a product that could be easily produced. It was lighter than stone, easy to mould and formed a wall that was fire resistant and durable. The practice of burning brick probably started with the observation that the brick was stronger and more durable. With the Industrial Revolution, traditional handwork procedures were replaced by machinery. Since then, further research and developments led to the creation of efficient brick making industries. Another component of masonry is the mortar, which traditionally, was mostly clay or lime mixed with sand and silty soil.

A first aspect related to masonry sustainability is its longevity and durability [x.14]. Structures that last longest, require less maintenance, and can be adapted for reuse cast a smaller shadow on the environment. Moreover, masonry recyclability is very high, helping saving virgin materials and reducing construction waste.

A second sustainability aspect in masonry is resource efficiency, as stone, earth and mortar (in its forms of lime or mud) are some of the most abundant materials found on earth. The manner in which materials are collected, transported short distances, and incorporated into manufactured products with relatively little energy provide minimal negative impact on the environment. Modern masonry manufacturers use more than $95 \%$ of extracted material in their production and the modular design of the manufactured block helps to reduce construction waste.

A third sustainability aspect in masonry is energy efficiency [x.15]. Masonry has high thermal mass, meaning that they provide very effective thermal storage. Masonry walls remain warm or cool long after the heat or air-conditioning has shut off. This benefit results in lower energy consumption in buildings. With proper design, either new or rehabilitated masonry walls, especially cavity walls, can reduce peak heating and cooling loads; shift peak loads; moderate indoor temperature swings; and reduce the size of HVAC systems. Also, passive design strategies can be successfully implemented utilizing masonry materials.

Others sustainability aspects in masonry are safety and protection, aesthetics, enclosure and finish, and natural fit. Masonry provides excellent fire safety and shelter from hurricanes, tornadoes, blasts, bullets and other. The variety of sizes, shapes, colours, textures and patterns available means that people will hold onto their attractive, inviting buildings longer and use them adaptively. Masonry walls can provide both structural support and exterior/interior finish. This simplified wall system can eliminate the need for additional materials that require manufacture, installation, maintenance and repair. This reduces cost and conserves building materials. Masonry is using natural materials, instead of oil-based chemical products. An overview of masonry and sustainability in given in [x.16]. 


\section{x.3.2 Wood}

Wood is a largely available material in most regions of the world. Since ancient times, it has been used by humans to build shelter, to light fires and to produce artefacts. It is not as durable as the stone; nevertheless, one can find several ancient buildings that use wood in their structures. Many centuries of building construction across the world made up a significant heritage of wood building know-how.

Wooden construction is empirically known for its sustainability. When performing a life-cycle analysis (LCA) of wooden buildings, it is usually considered that trees store carbon dioxide in their tissues, which will only be released by decay or combustion of wood. This wood feature is highlighted on long lifespan wood-based products, which are able to store carbon for a significant period of time, among which are the main construction materials [x.17]. In this discussion, [x.18] point out that the ability of wood to store carbon is not significant when compared to the total carbon emissions of building products manufacturing: as all the wood products have a finite life, being the $\mathrm{CO} 2$ released to the atmosphere by wood decay, the carbon storage balance will remain constant over time, considering that the overall of wood in worldwide use will eventually reach a steady state. Due to this fact, the carbon storage of wood products cannot offset the manufacturing emissions in the long term. In any case, the same author [x.18] concludes that wood products require small amounts of energy in its manufacture, comparing with bricks, aluminium, steel and concrete. In summary, the low energy requirements of wood products manufacturing is more significant towards the aim of carbon emission reduction in the long term, in comparison with the wood ability to store carbon.

Forestry industry has social and economic importance in many regions of the world. Besides that, it also contributes to control soil erosion, helps to regulate the climate and has a decisive role in the efficiency of the water cycle and on the biodiversity of wildlife and flora. Besides low energy requirements of wood products manufacture, it can be assumed that the transformation process of wood produces virtually no waste, since all the "waste" can be used for production of wood-based products or fuel, decreasing the demand for fossil fuels [x.19], [x.20]. Although wooden constructions need maintenance throughout its lifetime, the common wooden building systems allow partial replacement of modules or damaged elements, without compromising the entire structure. The use of wood also contributes to the energy efficiency of buildings, since it is a material with low thermal conductivity.

When dismantling a wooden building, the recovered wood can be directly reused in another building or used as raw material for wood-based products, either by extending its useful life or simply used as biofuel, avoiding the need for fossil fuels. On landfill, wood decomposes slowly, further extending carbon storage period. This is particularly efficient in modern landfills, equipped to capture methane emissions. Otherwise, the methane emissions partially offset the benefit from the carbon storage in the landfill [x.20]. Nevertheless, both combustion and decomposition of wood cause the release of the stored CO2 back to the atmosphere [x.18]. Some European countries do not allow wood deposition in landfill, because it is a combustible material. In these cases, wood residues have necessarily to be burned as biofuel or reprocessed in new products [x.21].

\section{x.4 Methodology for intervention in heritage structures}

Europe is the world leader in the field of conservation of cultural heritage buildings, from the very first approaches, through the Renaissance and the Industrial Revolution, to the first restoration theories and the Milan School. Until the end of the 19th century, the value of cultural heritage buildings was mostly associated to their use. With the end of the First World War, 
internationalization of culture received a boost and the famous early Charters for Conservation appeared, such as the Athens Charter for the Restoration of Historic Monuments [x.22], the International Charter for the Conservation and Restoration of Monuments and Sites [x.23] and the European Charter of the Architectural Heritage [x.24].

The first conservation attempts are nowadays considered outdated. They resulted in significant negative experience accumulated, such as blind confidence in modern materials and technologies, mistrust towards traditional materials and original structural resources, devaluation of ancient structural features, and insufficient importance attributed to diagnostic studies before an intervention. On the contrary, modern conservation respects authenticity of the ancient materials and building structure, meaning that interventions must be based on understanding the nature of the structure and the real causes of damage or alterations. Interventions are kept minimal, using an incremental approach, and much importance is attributed to diagnosis studies comprising historical, material and structural aspects. Only recently, in 2001, these aspects were condensed in a document issued by the International Council of Monuments and Sites, [x.25], recognizing that conventional techniques and legal codes or standards oriented to the design of new buildings may be difficult to apply, or even inapplicable, to heritage buildings, and stating the importance of a scientific and multidisciplinary approach involving historical investigation, inspection, monitoring and structural analysis. Many developments have recently been made, namely on investigation procedures for the diagnosis of historic fabric, e.g. [x.26] and structural analysis techniques, e.g. [x.27].

\section{x.4.1 Principles}

A multi-disciplinary approach is obviously required in any conservation or rehabilitation project and the peculiarity of cultural heritage buildings, with their complex history, requires the organization of studies and analysis in steps that are similar to those used in medicine. Anamnesis, diagnosis, therapy and controls, corresponding respectively to the condition survey, identification of the causes of damage and decay, choice of the remedial measures and control of the efficiency of the interventions. Thus, no action should be undertaken without ascertaining the likely benefit and harm to the building.

A full understanding of the structural behaviour and material characteristics is essential for any project. Diagnosis is based on historical information and qualitative and quantitative approaches. The qualitative approach is based on direct observation of the damage and material decay as well as historical and archaeological research, while the quantitative approach requires material and structural tests, monitoring and analysis. Often the application of the same safety levels used in the design of new buildings requires excessive, if not impossible, measures. In these cases other methods, appropriately justified, may allow different approaches to safety.

Therapy should address root causes rather than symptoms. Each intervention should be in proportion to the safety objectives, keeping intervention to the minimum necessary to guarantee safety and durability and with the least damage to heritage values. The choice between "traditional" and "innovative" techniques should be determined on a case-by-case basis with preference given to those that are least invasive and most compatible with heritage values, consistent with the need for safety and durability. At times the difficulty of evaluating both the safety levels and the possible benefits of interventions may suggest "an observational method", i.e. an incremental approach, beginning with a minimum level of intervention, with the possible adoption of subsequent supplementary or corrective measures.

The characteristics of materials used in restoration work (in particular new materials) and their compatibility with existing materials should be fully established. This must include long-term effects, so that undesirable side effects are avoided. 
Finally, a most relevant aspect is that the value and authenticity of cultural heritage buildings cannot be assessed by fixed criteria because of the diversity of cultural backgrounds and acceptable practices.

\section{x.4.2 Guidelines}

A combination of both scientific and cultural knowledge and experience is indispensable for the study of cultural heritage buildings. The purpose of studies, research and interventions is to safeguard the cultural and historical value of the building. The evaluation of a building frequently requires a holistic approach considering the building as a whole, rather than just the assessment of individual elements. The investigation of the structure requires an interdisciplinary approach that goes beyond simple technical considerations because historical research can discover phenomena involving structural issues while historical questions may be answered from the process of understanding the structural behaviour. Knowledge of the structure requires information on its conception, on its constructional techniques, on the processes of decay and damage, on changes that have been made and finally on its present state.

The recommended methodology for completing a project is shown in Figure 2, where an iterative process is clearly required, between the tasks of data acquisition, structural behaviour, and diagnosis and safety. In particular, diagnosis and safety evaluation of the structure are two consecutive and related stages on the basis of which the effective need for and extent of treatment measures are determined. If these stages are performed incorrectly, the resulting decisions will be arbitrary: poor judgment may result in either conservative and therefore heavy-handed conservation measures or inadequate safety levels. Evaluation of the safety of the building should be based on both qualitative (as documentation, observation, etc.) and quantitative (as experimental, mathematical, etc.) methods that take into account the effect of the phenomena on structural behaviour. Any assessment of safety is seriously affected by the uncertainty attached to data (actions, resistance, deformations, etc.), laws, models, assumptions, etc. used in the research, and by the difficulty of representing real phenomena in a precise way.

The methodology stresses the importance of an "Explanatory Report", where all the acquired information, the diagnosis, including the safety evaluation, and any decision to intervene should be fully detailed. This is essential for future analysis of continuous processes (such as decay processes or slow soil settlements), phenomena of cyclical nature (such as variation in temperature or moisture content), phenomena that can suddenly occur (such as earthquakes or hurricanes), and for future evaluation and understanding of the remedial measures adopted in the present. 


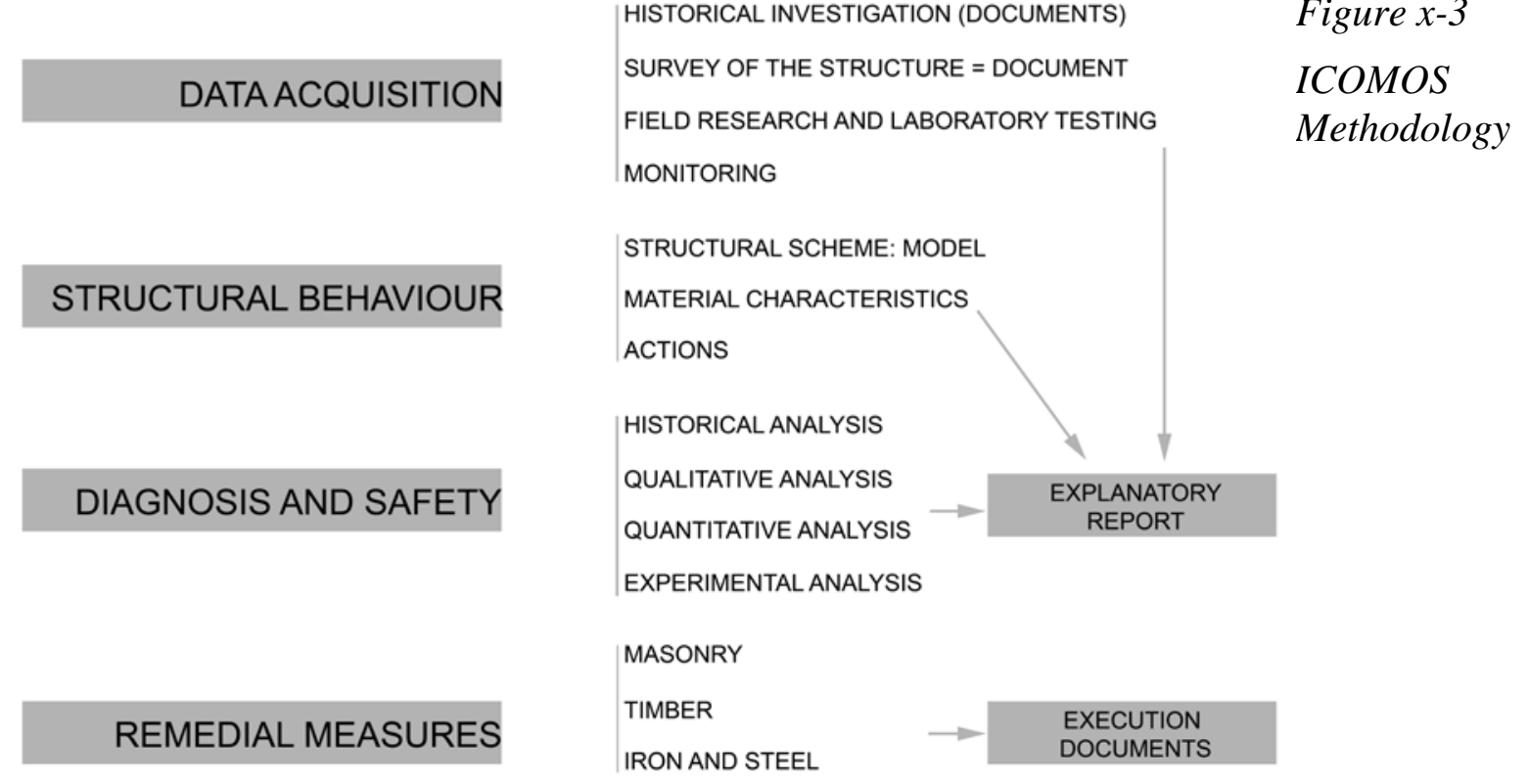

\section{x.5 Application of life-cycle assessment tools to existing buildings}

The life-cycle assessment (LCA) methodology is not designed to a specific kind of product, but can be applied to buildings, after the definition of a functional unit, for instance: "provide shelter to 4 people during a 50-year period, in predetermined comfort conditions”. ISO 14040:2006 [x.28] states "The essential property of a product system is characterized by its function and cannot be defined solely in terms of the final products". The boundary of a unit process is determined by the level of modelling detail that is required to satisfy the goal of the study. Nevertheless, it is important to fix a reference flow in each product system, expressed in the amount of products needed to fulfil the predefined function. An LCA study comprises four phases, namely: (a) the goal and scope definition phase; (b) the inventory analysis phase; (c) the impact assessment phase and (d) the interpretation phase. It is clearly stated in this standard that the reduction of LCA results to a single overall score or number is made by means of weighting, which requires value choices, therefore is not possible to perform it under a scientific basis

Life-cycle assessment (LCA) of buildings, according to ISO 14040:2006 [x.28], adaptable to new and existing buildings, is a methodology used to assess the actual and potential impacts of the life cycle of a product, from raw material acquisition through production, use, end-of-life treatment, recycling and final disposal. One of the core issues in LCA is the consideration of time. The time scale adopted in the analysis strongly influences the results of the assessment, as the impacts are distributed over a certain period of time, which influences its importance. In the specific case of heritage buildings, this feature may be highlighted. In fact, all data concerning building stock is time sensitive presenting historical, present and future time scales and very different time constants [x.11].

Through simulation, different periods can be linked, whereby the consequences of decisions can be appreciated. In practice, with respect to time issues, the period of the analysis should be determined according to the goals of the assessment. There are several options, including or excluding the existing structure: the analysis may start before the construction of the building, decades or centuries ago, with the calculation of all the present materials and the embodied energy related to their manufacturing and to the on-site construction, as well as all the conservation and maintenance operations performed throughout time. Alternatively, if the focus of the analysis is on the intervention and further utilisation of the ancient structure, the defined timeline may start at present, 
avoiding the quantification of the existing materials, as well as the energy embodied in the building. This second option is suitable, for instance, on the comparative analysis of several different rehabilitation strategies, in order to assess their impacts, dismissing the consideration of the existing fabric, due to the fact that it is common to all the options, therefore not producing any impact in the comparative results. Nevertheless, when the aim of the analysis is to assess the percentage of impacts related to the rehabilitation of the asset in its overall life cycle, the consideration of the existing structure may be important. The assessment of an ancient structure calls for an in-depth analysis of its features and materials, allowing an accurate quantification of the involved processes by the time of its original construction, which may be a time-consuming task.

In many cases, rehabilitation has been shown to be a sustainable process, due to the remarkable increase of the use phase. According to [x.11], from the resource conservation perspective, preliminary calculations show that conservation and transformation strategies induce significantly smaller mass-flows than new constructions over the average life time. Nevertheless, the difficulties presented by the assessment of the existing building stock demands the development of specific methodologies, in order to make its inclusion in LCA simpler and more feasible. There is a need for rapid and comprehensive evaluation methods to measure the resource value of buildings. Some aspects that should be included in the assessment of ancient buildings are the resource value, the protection of cultural diversity, as well as the preservation of historical or technical information that may be encapsulated in the building [x.11].

\section{x.6 Cultural heritage buildings and sustainability}

The reuse of existing buildings to suit the needs of the present and future generations, while avoiding demolition and reconstruction is one of the most sustainable forms of urban development [x.29].

\section{x.6.1 Environmental Impacts}

The reuse of existing structures and materials is, itself, a sustainable option under an environmental perspective, due to the avoidance of new products manufacturing, as well as the prevention of demolition operations and consequent residues production, with subsequent waste and landfill.

The increase of existing structures service life means that a past investment in energy and capital will be further amortised, avoiding new construction. Avoiding new construction, besides avoiding new materials production, further transport and energy consumption necessary to the construction phase will also be saved, with the pollution reduction associated ([x.29]; [x.30]). Moreover, the conservation of significant heritage values, by means of a 'green' adaptive reuse, provides economic, environmental and social benefits, which are the core of sustainable development [x.29].

\section{x.6.2 Economic impacts}

Environmental and economic impacts are usually related. The avoidance of new construction needs, while preventing materials and energy consumption related to a new construction, provides cost saves. Although there was a general line of thought that defended the conservation of historical centres and the development of cultural heritage as restriction to the economic development, present analyses show a complementarity between both [x.31]. Practice has shown that a well preserved heritage provides visibility and recognition of a region value and potential, developing feelings of belonging and pride to the inhabitants, as well as valorisation by foreigners.

Regarding labour and employment issues, rehabilitation may play an important role, due to the intensive labour that it requires, comparing with modern construction practice. To support this statement, [x.30] shows that rehabilitation of historic buildings in Norway allowed the creation of $16.5 \%$ more direct jobs, not to mention the $26.7 \%$ indirect jobs, in comparison with new construction industry. 
Besides the direct effects of construction, the investment in cultural heritage produces effects in tourism and on intangible values, like the public popularity of history. Therefore, its secondary effects may be linked to the generation of economic value [x.32], although it may be hard to quantify it precisely, due to the multiplicity of influences and effects related to the phenomenon. The consideration of secondary effects should also be addressed by the specific assessment methodologies currently under development.

\section{x.6.3 Social impacts}

Social impacts, in the overall sustainability assessment, are a more recent concern, comparing with economy and environment issues. For this reason, and because impacts in society are frequently the result of multiple influences that are difficult to measure, this sustainability dimension is the least developed so far, remaining rather subjective. Nevertheless, some aspects of rehabilitation of cultural heritage buildings should be assessed and must be considered in the social analysis, namely: the promotion of collective memory, improving people's relationship with history; the effects of job creation on local communities, especially the ones that need the investment in economical activities that enable population to remain in the region, avoiding emigration; and the importance of ancient techniques recovery to the intangible heritage, namely through the preservation of traditional building know-how, that would otherwise be lost.

Through the rehabilitation process local craftsmen have been trained and gained experience in traditional building techniques, and today some of these are being "exported" to other sites or regions to assist in rehabilitation projects or educate other craftsmen. This is a secondary effect linked to the heritage strategy [x.13].

\section{x.7 Conclusions}

Rehabilitation of cultural heritage buildings plays an important role in sustainability policies, mainly due to its role in: (a) the documentation of ancient knowledge, practice and culture, among others, which should be used on actual source of improvement; (b) the reuse of existing structures, frequently made of sustainable building materials like masonry and wood; (c) the promotion of historic values and local valorisation, which produce positive impacts both in economy and society; (d) promotion of job creation, due to the labour-intensive techniques used.

\section{x.8 References}

[x.1] European Commission: Europe, the world's No 1 tourist destination - a new political framework for tourism in Europe, COM (2010) 352. http://eur-lex.europa.eu/

[x.2] Ecorsys scs Group: Study on the Competitiveness of the EU tourism industry, 2009. http://ec.europa.eu/

[x.3] FEMA: Fact sheet - Mitigation's value to society, Federal Emergency Management Agency, 2011.

[x.4] MMC: Natural Hazard Mitigation Saves: An Independent Study to Assess the Future Savings from Mitigation Activities. Volume 1 - Findings, Conclusions and Recommendations. Volume 2 - Study Documentation, Multihazard Mitigation Council of the National Institute of Building Sciences, 2005.

[x.5] World Bank: Natural hazards, unnatural disasters: The economics of effective prevention, The World Bank and The United Nations, 2010. 
[x.6] Sanghi, A.: Presentation on "Natural hazards, unnatural disasters: The economics of effective prevention”, The World Bank, 2010.

[x.7] UNISDR: Global assessment report on disaster risk reduction, United Nations International Strategy for Disaster Reduction Secretariat, ISBN 9789211320282, 2009, 207 pp.

[x.8] U.S.G.S.: U.S. Geological Survey, accessed 27/01/2012. http://www.usgs.gov/

[x.9] ICCROM: Definition of Cultural Heritage. Revised in Jokilehto, J. (2005), Definition of Cultural Heritage: References to documents in history, ICCROM Working Group "Heritage and Society"

[x.10] (SUIT, 2001).

[x.11] Kohler, N. \& Hassler, U.: The building stock as a research object, Building Research \& Information, 30:4, 2002, 226-236.

[x.12] The Nara Document on Authenticity, International Council on Monuments and Sites, 1994. http://www.international.icomos.org/charters/nara-e.pdf

[x.13] Bowitz, E. \& Ibenholt, K.: Economic impacts of cultural heritage - Research perspectives, Journal of Cultural Heritage, 10, 2009, 1-8.

[x.14] Grimm, C.T.: Durability of Brick Masonry: A Review of Literature,” Masonry: Research, Application, and Problems, ASTM STP 871, J.C. Grogan and J.T. Conway, Eds., American Society for Testing and Materials, Philadelphia, 1985, 202-234.

[x.15] Reddy, B.V.V. \& Jagadish, K.S.: Embodied energy of common and alternative building materials and technologies, Energy and Buildings, 35(2), 2003, 129-137.

[x.16] Verhelst, F., Kjaer, E., Jäger, W., Middendorf, B., Van Balen, K. \& Walker, P.: Masonry - sustainable, contemporary and durable: Anachronism, bold statement or visionary outlook?, Mauerwerk 15(2), 2011, 118-122.

[x.17] Borjesson, P., \& Gustavsson, L.: Greenhouse gas balances in building construction: wood versus concrete from life-cycle and forest land-use perspectives. Energy Policy (28), 2000, 575-588.

[x.18] Buchanan, A., \& Levine, S.: Wood based building materials and atmospheric carbon emissions. Environmental Science \& Policy (2), 1999, 427-437.

[x.19] Sathre, R., \& Gustavsson, L.: Using wood products to mitigate climate changes: External costs and structural change. Applied Energy (89), 2009, 251-257.

[x.20] Lippke, B., Wilson, J., Meil, J., \& Taylor, A.: Characterizing the importance of carbon stored in wood products. Wood and Fiber Science (42, Corrim Special Issue), 2010, 5-14.

[x.21] Dodoo, A., Gustavsson, L., \& Sathre, R.: Carbon implications of end-of-life management of building materials. Resources, Conservation and Recycling (53), 2009, 276-286.

[x.22] Athens Charter for the Restoration of Historic Monuments, International Council on Monuments and Sites, 1931. http://www.icomos.org/en/charters-and-texts/179-articles-enfrancais/ressources/charters-and-standards/167-the-athens-charter-for-the-restoration-ofhistoric-monuments

[x.23] International Charter for the Conservation and Restoration of Monuments and Sites, International Council on Monuments and Sites, 1964. http://www.icomos.org/charters/venice_e.pdf 
[x.24] European Charter of the Architectural Heritage, International Council on Monuments and Sites, (1975). http://www.unescobkk.org/fileadmin/user_upload/culture/cultureMain/Instru-ments/European_Charter.pdf

[x.25] ICOMOS: Recommendations for the Analysis and Restoration of Historical Structures, ISCARSAH, 2003.

[x.26] Binda L, Saisi, A., \& Tiraboschi, C.: Investigation procedures for the diagnosis of historic masonries, Construction and Building Materials, 14(4), 2000, 199-233.

[x.27] Lourenço, P.B., Mendes, N., Ramos, L.F. \& Oliveira, D.V.: Analysis of masonry structures without box behavior, International Journal of Architectural Heritage, 5, 2011, 369-382.

[x.28] ISO 14040: Environmental management - life cycle assessment - Principles and framework. International Organization for Standardization. Geneva, Switzerland, 2006.

[x.29] Yung E.H.K. \& Chan, E.H.W.: Implementation challenges to the adaptive reuse of heritage buildings: Towards the goals of sustainable, low carbon cities. Habitat International, 36 (3), July 2012, 352-361.

[x.30] Gražulevičiūte, I.: Cultural Heritage in the Context of Sustainable Development. Environmental research, engineering and management, N. ${ }^{\circ} 3(37), 2006$, pp 74-79.

[x.31] Fusco Girard, L. \& Nijkamp, P.: Le valuazioni per lo sviluppo sostenibile della cittá e del territorio, FrancoAngeli, Milano, 1997.

[x.32] Stubbs M.: Heritage-sustainability: developing a methodology for the sustainable appraisal of the historic environment, Planning Practice \& Research, 19:3, 2004, 285-305. 